\title{
ESCALA E TEMPO NA ANÁLISE DA PAISAGEM
}

\section{Scale and time in landscape analysis}

\author{
Evelyn de Castro Porto Costa \\ Mestranda do Programa de Pós-Graduação em Geografia da UERJ-FFP \\ evelynportocosta@yahoo.com.br \\ Vinicius da Silva Seabra \\ Professor Adjunto do Departamento de Geografia da UERJ-FFP \\ vinigeobr@yahoo.com.br
}

Artigo enviado para publicação em 28/04/2019 e aceito em 17/06/2019

DOI: $10.12957 /$ tamoios.2019.42275

\begin{abstract}
Resumo
O conceito de escala é de suma importância para estudos geográficos de qualquer natureza, sendo importante compreender as definições desse conceito para realizar escolhas adequadas da escala em estudos geográficos. A escala espacial e a temporal são variáveis importantes na delimitação da área de estudos, sendo o fenômeno estudado responsável pela escolha mais apropriada das escalas. Também é relevante ressaltar que com o desenvolvimento das geotecnologias, a perspectiva escalar ganha destaque nas imagens de sensoriamento remoto, tendo em vista a correlação desse conceito com as generalizações cartográficas e detalhamento do objeto. Nesse sentido, este trabalho discute os conceitos de escala, apresentando sua importância para os estudos geográficos, dando ênfase na análise da paisagem em perspectivas espaço-temporais. Para o presente estudo foram realizados levantamentos bibliográficos de autores que trabalham com o conceito de escala em diferentes perspectivas, utilizando exemplos do uso de escalas em estudos geográficos.
\end{abstract}

Palavras-Chave: Escala Espacial; Escala Temporal; Análise da Paisagem; Geotecnologias.

\begin{abstract}
The concept of scale is of paramount importance for geographic studies of any nature, and it is important to understand the definitions of this concept to make appropriate scale choices in geographic studies. Spatial and temporal scales are important variables in the area delimitation and studies, and the studied phenomenon is responsible for the most appropriate choice of scales. It is also important to note that with the development of geotechnologies, the scalar perspective is highlighted in remote sensing images, considering the correlation of this concept with cartographic generalizations and object detailing. In this sense, this paper discusses the concepts of scale, presenting its importance for geographic studies, emphasizing landscape analysis in space-time perspectives. For the study, we carried out bibliographic surveys of authors who work with the concept of scale in different perspectives, using examples of the use of scales in geographic studies.
\end{abstract}

Keywords: Spatial Scale; Temporal Scale; Landscape Analysis; Geotechnology. 


\section{Introdução}

É necessário compreender a relação da escala com a análise da paisagem, dessa forma, considerar as principais definições e distinções entre os conceitos de escala cartográfica, geográfica e temporal nos possibilita compreender a importância dos recortes têmporo-espaciais delimitados em trabalhos científicos.

As pesquisas ambientais de qualquer natureza priorizam primeiramente a definição de escala para o seu estudo, seja ela espacial e temporal, pois é a partir delas que a o pesquisador terá a segurança para interpretar e compreender os dados gerados, bem como ter a garantia de seus resultados para dialogar com os objetivos propostos pelo estudo.

Outro aspecto importante que deve ser mencionado são as noções de escala nas geotecnologias, tendo em vista sua grande importância nos dias atuais para as análises da paisagem. Dessa forma, cabe discutir as generalizações de escala na perspectiva das imagens de sensoriamento remoto, abordando as limitações e distinções de escalas nos diferentes tipos de resoluções espaciais.

Logo, o presente trabalho tem a pretensão de discutir a importância da escala espacial e temporal na análise da paisagem, partindo do pressuposto de compreender definições do conceito de escala e sua importância para diferentes estudos geográficos. Buscaremos também dar ênfase a influência das geotecnologias para o conceito de escala, tendo em vista a importância das imagens de satélite para a realização de mapeamentos.

\section{A importância da escala na análise da paisagem}

Para os estudos ambientais é de suma importância à prévia delimitação da área de estudos, para assim, facilitar a adoção das metodologias que serão utilizadas nas análises. É nesse sentido que a discussão de escala merece atenção e protagonismo, pois é a partir dela que será possível adotar medidas e iniciar os estudos de forma otimizada e completa.

A escala nos possibilita analisar a paisagem de diferentes maneiras. Menezes e Netto (1999) afirmam que a escala é fundamental em pesquisas de cunho geográfico, cartográfico, ambiental, ou qualquer outra que se realize sobre o espaço físico de atuação de um fenômeno, "espacializando" a sua representação.

Kohler (2001), por sua vez, aborda a importância da escala para os estudos geomorfológicos. Ele aponta que a escala de estudo de um relevo irá determinar as estratégias e técnicas de abordagem da análise geomorfológica. Tal aspecto se aplica aos demais estudos geográficos. Sendo assim, a escolha da escala é fundamental nas análises espaciais de quaisquer fenômenos, sejam ambientais ou sociais, sendo a escala um dos aspectos fundamentais de uma pesquisa geográfica e cartográfica, pois é nela que se possibilitará obter resultados que atendam ao real objetivo dos estudos.

Correlacionado o conceito de escala às análises da paisagem, é possível compreender que as definições de escala, sejam elas, temporais ou espaciais, são consideradas elementos de grande relevância para as análises da paisagem. É nesse sentido que Bertrand (1971) afirma que a noção de escala é inseparável do estudo das paisagens.

Seabra (2009) aponta que o emprego incorreto de alguns conceitos e/ou técnicas cartográficas podem nos levar a representações equivocadas da superfície terrestre, resultando muitas vezes em interpretações errôneas dos fenômenos ou processos presentes no espaço geográfico. Nesse sentido, é importante enfatizar que a noção de escala possui diferentes abordagens e concepções, o que interfere diretamente na definição de seu conceito e consequentemente em sua aplicação. Segundo Castro (1992), 
devido à falta de clareza nas definições de escala geográfica, os geógrafos tendem a confundir este conceito com o de escala cartográfica.

Dessa forma, faz-se necessário categorizar tais conceitos de forma a compreender o tipo de escala que está sendo abordado, possibilitando um melhor entendimento dos diferentes tipos de escala que esse trabalho presente abordar.

Inicialmente, a primeira distinção que deve ser levada em consideração é a das concepções de escala para a geografia e para a cartográfica, pois ambos são importantes nos estudos geográficos. Dessa forma, é importante enfatizar que a escala geográfica é diferente da escala cartográfica. A escala geográfica está relacionada com a extensão geográfica da área em estudos, logo, representa a sua espacialidade e seu recorte espacial a ser analisado. Já a escala cartográfica está associada à representação espacial desse recorte de forma cartográfica através de mapas; dessa forma, a escala cartográfica possibilita a associação daquela representação com o mundo real.

Ilustrando a relação entre escala cartográfica e geográfica é necessário compreender as suas associações e correlações:

A relação das escalas cartográfica e geográfica é inversamente proporcional, ou seja, quanto maior for a área compreendida por um fenômeno, menor deverá ser a escala cartográfica adequada para a sua representação e quanto menor for a área de ocorrência de um fenômeno, maior deverá ser a escala cartográfica necessária para a sua representação (MARQUES E GALO, 2009, p.49).

Menezes e Netto (1999) também destacam que escalas cartograficamente maiores representam um nível de detalhamento maior que em escala menores, abordando por sua vez uma área geográfica menor. Isto, por sua vez, leva também ao estabelecimento de um nível de detalhamento da própria informação que esteja sendo representada.

É sobre essa perspectiva que é necessário destacar a importância da cartografia nas representações espaciais, levando em consideração os elementos cartográficos que poderão ser representados ou negligenciados a partir da escala cartográfica. Nesse sentido, a tabela 1 traz informações da correlação entre escala grande e pequena, bem como sobre a quantidade de informações disponíveis. Além disso, cabe destacar o grau de generalização, e consequentemente, a perda de detalhes que ocorre conforme a variação da escala geográfica.

Tabela 1. Quadro de distinções entre a escala cartográfica e geográfica.

\begin{tabular}{c|c|c|c|c}
$\begin{array}{c}\text { Escala } \\
\text { Geográfica }\end{array}$ & $\begin{array}{c}\text { Escala } \\
\text { Cartográfica }\end{array}$ & Generalização & $\begin{array}{c}\text { Exemplo de escala } \\
\text { geográfica }\end{array}$ & $\begin{array}{c}\text { Exemplo de escala } \\
\text { cartográfica }\end{array}$ \\
\hline Grande & Pequena & $\begin{array}{c}\text { Mais } \\
\text { Generalizado }\end{array}$ & $\begin{array}{c}\text { Estado do Rio de } \\
\text { Janeiro }\end{array}$ & $1: 1.500 .000$ \\
\hline Pequena & Grande & $\begin{array}{c}\text { Menos } \\
\text { Generalizado }\end{array}$ & $\begin{array}{c}\text { Bairro de Figueira } \\
\text { (Arraial do Cabo) }\end{array}$ & $1: 10.000$ \\
\end{tabular}

Fonte: $\mathrm{O}$ autor 
Menezes e Fernandes (2013), ao discutirem o conceito de escala em uma perspectiva cartográfica, apontam que a escala é essencial para qualquer tipo de representação espacial, uma vez que qualquer visualização gráfica é elaborada segundo uma redução do mundo real. Logo, na concepção mais técnica, que busca padronizar o uso de escalas para as representações espaciais, é importante considerar à proporção que o mundo real foi reduzido para ser representado em tamanho menor. É desse modo que extraímos a escala cartográfica de um mapeamento.

\section{A escala geográfica/espacial}

Dentro do contexto espacial, a escala estará sempre presente em qualquer nível de estudos geográficos e cartográficos, sendo considerada como fator determinante para a delimitação de espaço físico, grau de detalhamento de uma representação ou identificação de feições geográficas (MENEZES E NETTO, 1999).

A escala geográfica está relacionada à sua amplitude espacial, ou seja, a extensão e a definição de limites espaciais nas análises a serem realizadas, podendo ser vista como a escala ou o recorte do estudo. Goodchild e Quattrochi (1997) afirmam que a escala geográfica é importante porque define os limites das nossas observações da Terra. Da mesma forma Oliveira (2011), aponta que a escala geográfica pode ser observada a partir da lógica espacial dos fenômenos.

Entretanto, é necessário ressaltar que o conceito de escala geográfica aqui abordada também é referido por alguns autores, como escala espacial, sendo estes conceitos (escala espacial e escala geográfica) tratados como sinônimos e visto por ambos os nomes na literatura.

Um aspecto significativo ao considerar uma escala são os elementos que são inviabilizados de acordo com sua escala espacial, tal como, os elementos do entorno, que podem ser oprimidos ao ter uma escala espacial grande e podem ser fundamentais para $\mathrm{o}$ entendimento da dinâmica da paisagem. Nesse sentido, Zacharias (2006) aponta que em determinadas escalas (maiores) alguns fatores não aparecem, ou mesmo são visíveis. Neste caso, faz-se necessário mudar de escala, o que repercute na perda da visão de alguns destes fatores/agentes.

É importante destacar que a percepção de escala varia de acordo com o fenômeno em análise, logo, é necessário pensar sobre a escala espacial mais apropriada para determinados objetivos. A observação de fenômenos sob diferentes escalas pode causar significativas alterações na sua interpretação, gerando, portanto, questionamentos sobre o impacto da observação de um fenômeno (MENEZES E NETTO, 1999). A partir da figura 1 é possível identificar dois tipos de escalas, uma escala menor, com menos detalhes, e uma escala maior, com maiores detalhes. 
Figura 1. Ilustração comparativa entre escala espacial grande e pequena

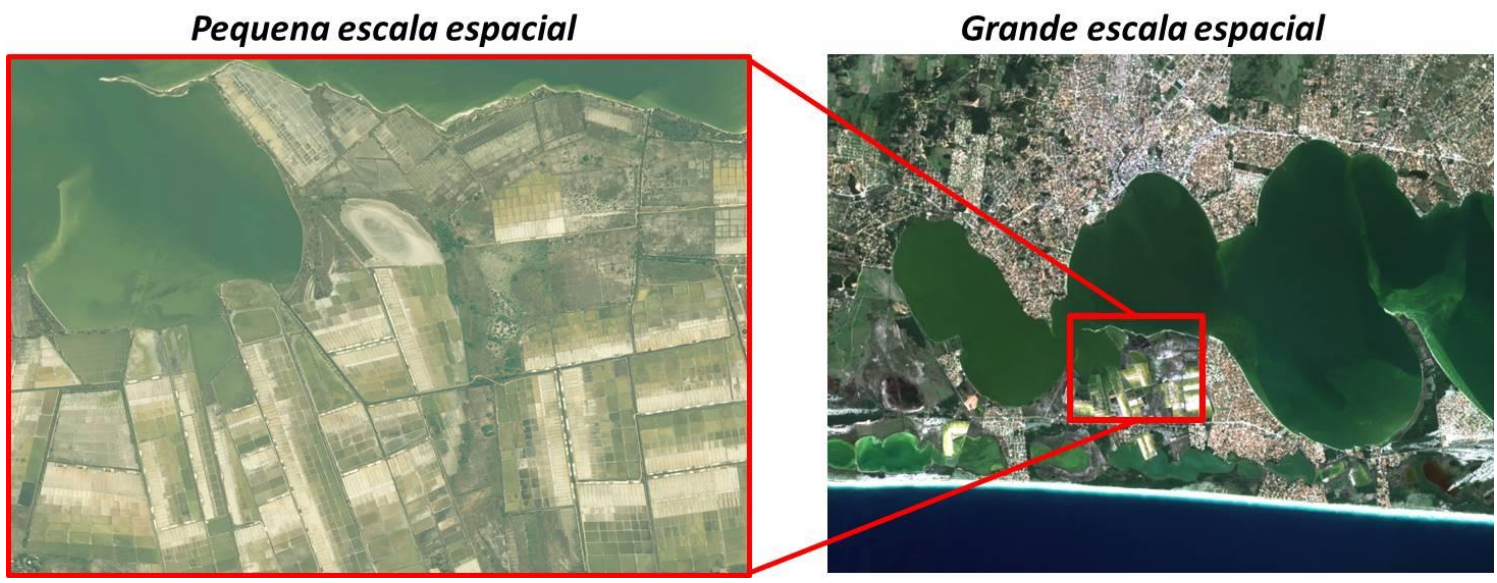

Fonte: $\mathrm{O}$ autor

A primeira possui uma observação da área de menor escala espacial, e consequentemente maior escala cartográfica. Essa dimensão de escala permite análises a nível local, priorizando a individualidade do objeto observado. E, o segundo recorte, contemplando a mesma área em análise, entretanto, em uma área de maior escala espacial, contendo informações do entorno, possibilitando assim, a compreensão do contexto na qual o objeto está inserido.

\section{As perspectivas da escala temporal}

A escala pode estar presente na perspectiva espacial e/ou temporal. Segundo Menezes e Netto (1999), a escala temporal é importante para o estudo de uma grande quantidade de fenômenos, sendo muitas vezes aplicada em conjunto com a escala espacial, principalmente para a indicação de elementos ligados a fatores evolutivos e ambientais, como seus períodos de ocorrência e atuação.

Monteiro (2000) enfatiza a necessidade de se considerar as escalas temporais nos estudos geográficos. A perspectiva temporal permite analisar um fenômeno de forma histórica, possibilitando compreender a frequência, padrões e interações nas dinâmicas espaço-temporais dos eventos.

A escala temporal proporciona aos estudos geográficos uma perspectiva mais ampla das ocorrências de fenômenos ambientais e sociais, possibilitando análises mais completas para o entendimento das dinâmicas da paisagem atual, pois, ao conhecer as características anteriores é possível inferir na sua estrutura e consolidação presente.

Além disso, a escala temporal pode promover entendimentos complexos e profundos sobre a geomorfologia, litologia, mudanças climáticas, ações antrópicas, etc. É nessa lógica em que Troll (1997) destaca que a paisagem reflete as transformações temporais, conservando testemunhos pretéritos. Desse modo, é possível compreender que a própria paisagem resguarda indícios e provas concretas dessas mudanças, podendo ela (a paisagem), ser o objeto de estudos mais apropriado para a análise temporal dessas mudanças.

Uma consideração relevante é que essas transformações podem ser naturais ou antrópicas, sendo em ambos os casos, variadas de acordo com o fenômeno a ser estudado. Kohler (2001) aponta exemplos de análises temporais na geomorfologia, segundo o autor, por exemplo, a deriva continental (pequena escala) é medida em milímetros /ano, já a evolução de uma voçoroca (grande escala) é medida em metros/ano e a evolução de um sulco num paredão calcário (lapiás) em milímetros / minuto. 
Como exemplo da escala temporal, apresenta-se na figura 2, um modelo do uso de materiais cartográficos em perspectiva histórica. A presente figura representa três momentos históricos distintos entre o século XX e XXI especificamente correspondentes ao ano de 1929, 1976 e 2017.

Figura 2. Escala temporal de análises da paisagem

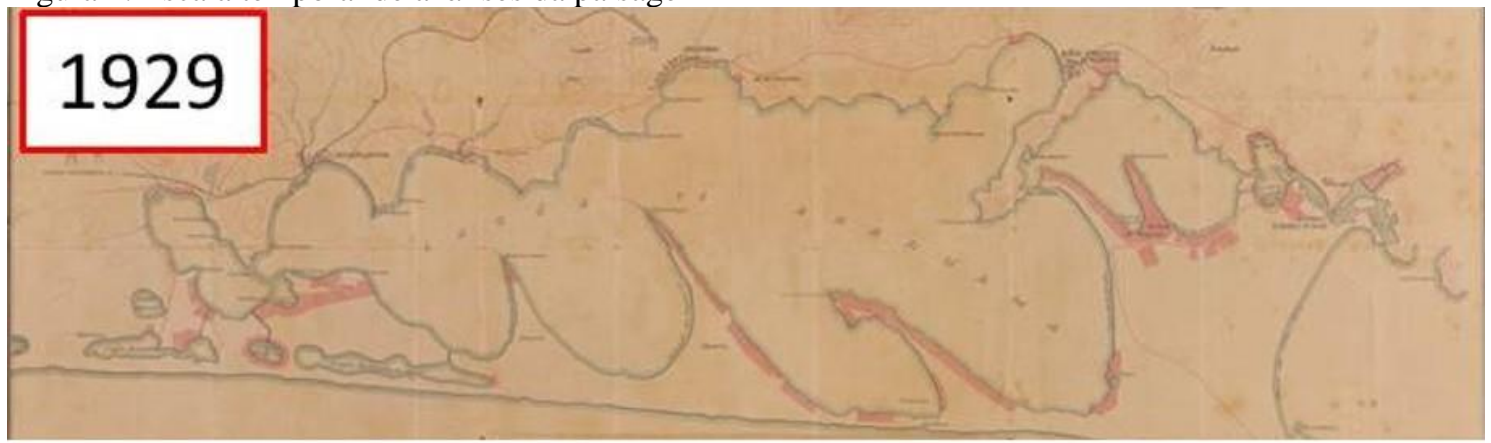

(a)

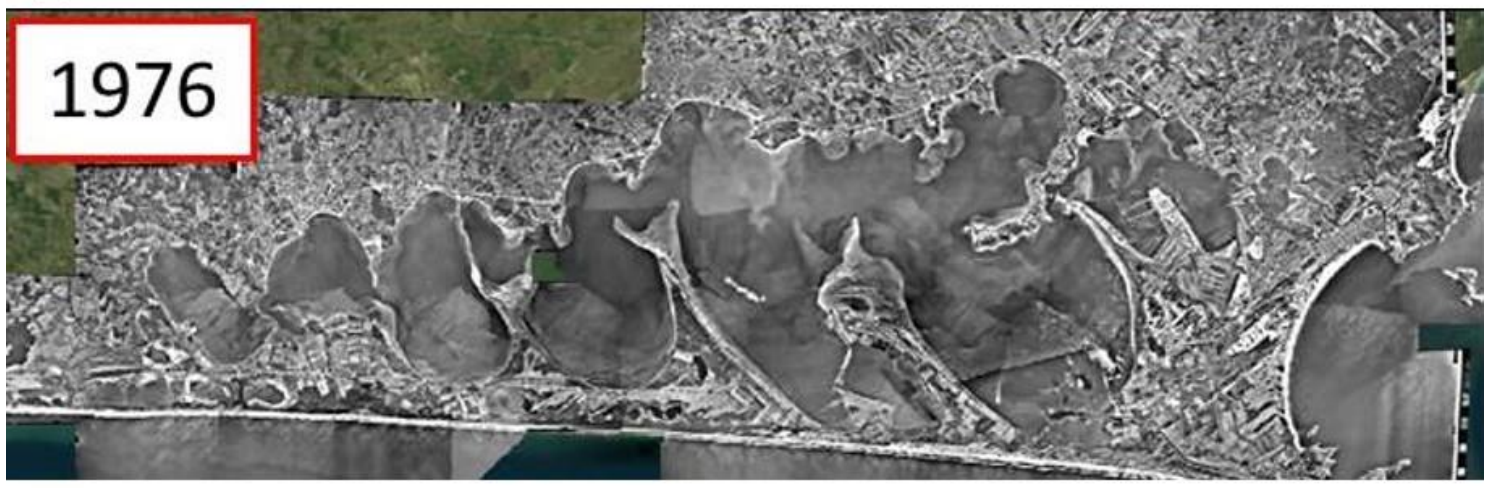

(b)

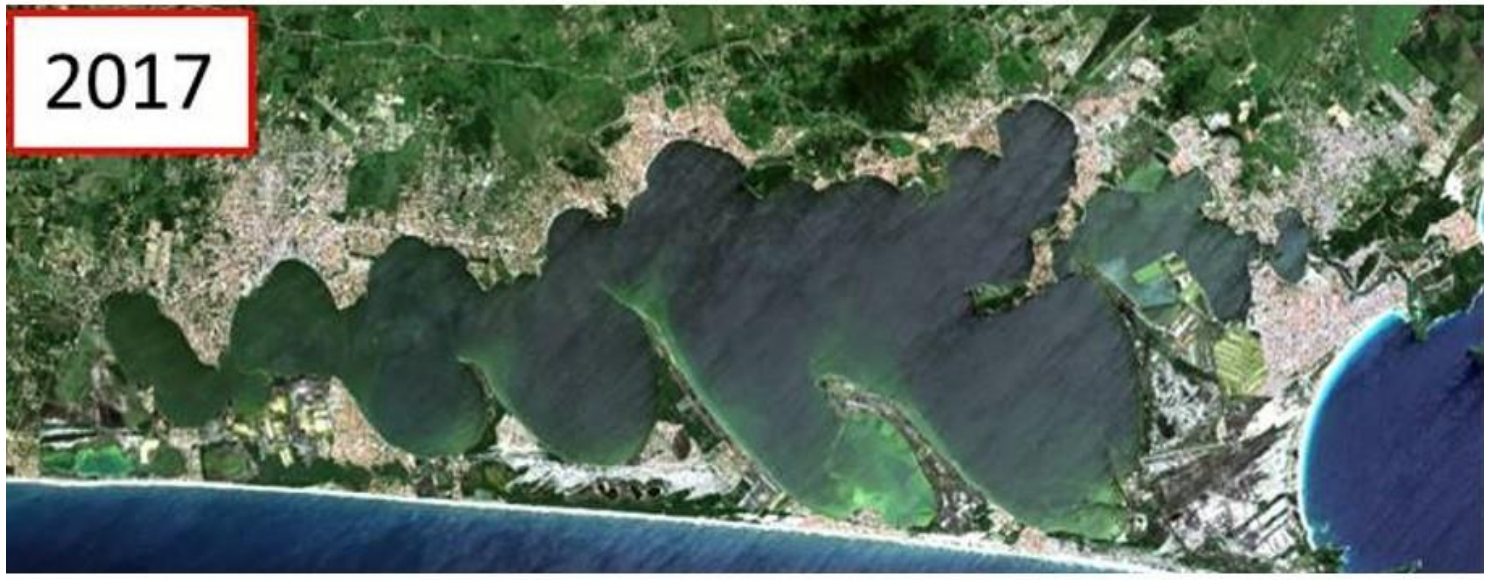

(c)

Legenda: (a) mapa histórico do ano de 1929 (Arquivo Nacional); (b) fotografia aérea do ano de 1976 (Força Aérea Brasileira); (c) imagem de satélite do ano de 2017 (Agência Espacial Europeia).

Fonte: $\mathrm{O}$ autor.

Tais representações auxiliam nas análises espaciais inerentes aos estudos geográficos, permitindo compreender as dinâmicas evolutivas da paisagem, bem como suas transformações. Possibilitando explicar fenômenos e prognosticar cenários futuros. 


\section{Resoluções de imagens e escala: generalizações}

Outro elemento fundamental para esta pesquisa é a generalização, que muito está associada à escala cartográfica. As generalizações são responsáveis pela perda de detalhes e informações de uma representação, que são realizadas principalmente através dos mapas.

Para Menezes e Netto (1999), quanto maior for a generalização, mais distante da realidade a representação cartográfica estará. Nesse sentido a finalidade da representação está diretamente associada a possibilidade de generalização, devido ao grau de importância de cada elemento representado, dando ênfase ou subestimando certas informações que não são úteis para a finalidade daquele tipo de mapeamento.

Logo, a finalidade do mapeamento diz respeito ao emprego do mapa, para que ele vai servir, ou a que tipo de usuário deverá atender. Assim, são definidas quais informações que serão importantes e deverão estar contidas no mapa, em função do seu emprego e dos usuários que o utilizarão (MENEZES e FERNANDES, 2013).

Além disso, a generalização cartográfica é um fator determinante para um mapeamento, podendo implicar em desdobramentos desagradáveis para a tomada de decisão. Segundo Goodchild e Quattrochi (1997), para um tomador de decisão, a generalização associada à escala pode ser uma maneira de obscurecer a informação que é vital para uma decisão correta, particularmente quando a informação deve ser integrada a partir de várias ciências e fontes.

As generalizações podem ocorrer na representação dos dados, podendo estar diretamente associado às imagens de satélite, que são utilizadas para elaboração de dados espaciais. Dessa forma, a generalização está correlacionada ao grau de detalhamento que a imagem possui para a escala que está sendo representada. Esse detalhamento deve ser avaliado de acordo com a resolução espacial das imagens, bem como, a escala espacial em análise.

No sensoriamento remoto a escala está associada ao tamanho do pixel, ou seja, à resolução espacial. A resolução espacial também é vista como o menor objeto ou feição que pode ser distinta em um conjunto de dados (GOODCHILD e QUATTROCHI, 1997). Segundo Florenzano (2011), a resolução espacial é a capacidade de o sensor discriminar objetos em função do tamanho destes.

Todas as resoluções são importantes para a definição do grau de detalhamento. Se por um lado a espacial ajuda na identificação dos alvos segundo o seu tamanho, a espectral e radiométrica contribuem na definição dos alvos de acordo com a matéria (substância) que os compõem. É errado considerar só a resolução espacial.

As imagens de satélite possuem uma grande associação com as generalizações cartográficas, devido a diversidade de sensores remotos e suas distintas resoluções espaciais, que estão diretamente associadas ao tamanho do pixel da imagem. Por exemplo, em pequenas escalas costuma-se utilizar imagens orbitais, que abrangem consideráveis porções do terreno, mas as baixas resoluções espaciais, por outro lado, trabalhando em escalas maiores, faz-se o uso de fotografias aéreas (pequenas áreas, altas resoluções). (KOHLER, 2001).

Uma mudança da pequena dimensão implica uma mudança na resolução, ou metaforicamente, um movimento do olho observador em direção ou para longe da superfície (GOODCHILD e QUATTROCHI, 1997). É importante destacar que os sensores remotos variam em seus tipos de resoluções, estando à escolha do sensor mais apropriado diretamente associados ao objetivo de estudo. Dessa forma, não é correto afirmar que sensores com baixas ou médias resoluções espaciais são escolhas inapropriadas, devido às demais características dos sensores que podem auxiliar de 
$\overline{\text { melhor forma nas análises, tal como as resoluções temporais, radiométricas, espectral, }}$ etc.

A figura 3 traz o recorte espacial de uma mesma área no município de Araruama, em escalas cartográficas distintas. A partir do mesmo recorte é possível comparar as resoluções espaciais das imagens de satélite de média resolução espacial (Sentinel 2) e de alta resolução espacial (WorldView 2).

A imagem de alta resolução possui uma resolução espacial de 2 metros, ou seja, é possível distinguir objetos de até $4 \mathrm{~m}^{2}$ metros na imagem, possibilitando distinguir os objetos visualmente, devido a definição detalhada dos objetos. Já a imagem com resolução de 10 metros, possui a limitação de identificação de objetos acima de 10 metros, dessa forma, os objetos possuem uma característica homogênea, dificultando a distinção entre os objetos nesse nível de detalhe.

Figura 3. Comparativo de resoluções espaciais entre imagens de satélite do sensor WorlView 2 e Sentinel2.

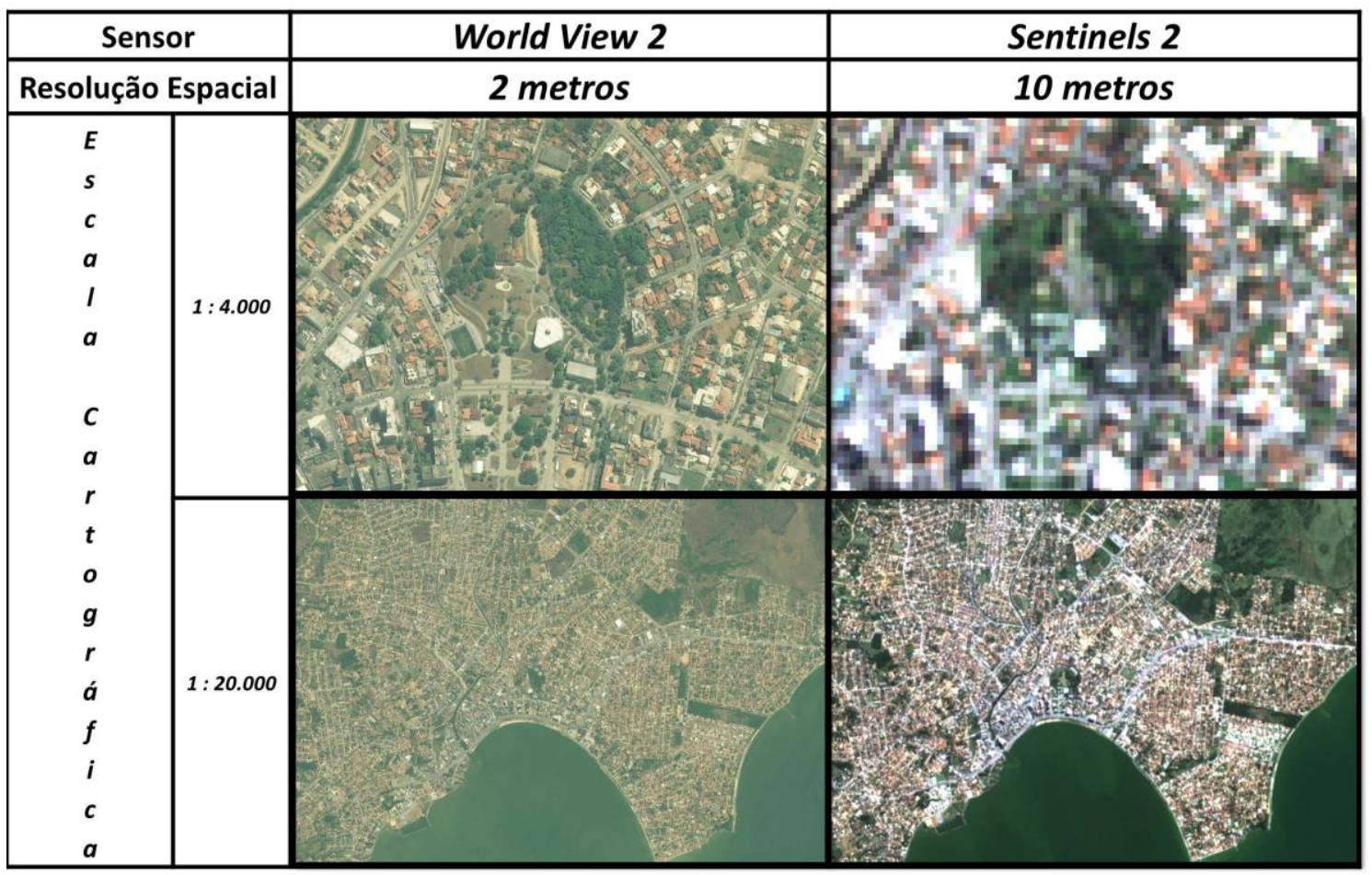

Fonte: do autor

No zoom em escala de 1:4.000 é possível notar a grande diferença entre as imagens de alta e média resolução espacial, pois trata-se de um recorte espacial que contempla o local, com menos informações do entorno e mais ênfase a uma área especifica. Nesse recorte é necessário reconhecer a importância de fazer as análises em uma imagem de alta resolução, pois, permitirá uma análise menos generalizada dos objetos existentes na imagem.

Já no zoom em escala de 1:20.000 a distinção dos objetos entre as imagens se torna irrisória, devido a escala geográfica trabalhada, que contempla uma área geográfica mais ampla e não requer grandes detalhamentos dos objetos existentes, permitindo bons resultados no mapeamento de ambas as imagens (alta e média resolução espacial), pois, na escala em análise, os alvos a serem identificados não sofrerão grandes processos de generalização. 


\section{As geotecnologias como uma possibilidade de análise da paisagem}

Uma das potencialidades para o estudo da paisagem se remete aos recursos disponíveis no uso das geotecnologias, que são ferramentas que permitem análises espaciais para diferentes objetivos, podendo ser empregada em diferentes perspectivas cientificas.

As geotecnologias são compostas por soluções em hardware, software $e$ peopleware, que juntas, constituem poderosas ferramentas para tomada de decisão. Dentre as geotecnologias podemos destacar: Sistemas de Informação Geográfica (SIG), Cartografia Digital, Sensoriamento Remoto (SR), Sistema de Posicionamento Global (GNSS), Georreferenciamento, Processamento de Imagem (PDI) (ROSA, 2005).

Florenzano (2011) afirma que o SIG é a ferramenta computacional do geoprocessamento, disciplina que utiliza técnicas matemáticas e computacionais para $\mathrm{o}$ tratamento da informação geográfica. Segundo Câmara et al (2001), o geoprocessamento é uma tecnologia interdisciplinar, que permite a convergência de diferentes disciplinas científicas para o estudo de fenômenos ambientais e urbanos.

Sendo assim, o SIG permite armazenar, processar, integrar, analisar, calcular áreas, visualizar e representar informações georreferenciadas (FLORENZANO, 2011). O SIG ao lado de outros instrumentos pode apoiar decisões de planejamento adequadas para o meio ambiente e intersubjetivamente registradas e repetíveis (LANG E BLASCHKE, 2009).

Dentro das geotecnologias, o sensoriamento remoto surge como importante recurso tecnológico para análises de paisagem. Para as tarefas de preservação do meio ambiente e da natureza, os dados espaciais confiáveis e os parâmetros de geoecologia da paisagem são de grande importância. (LANG E BLASCHKE, 2009). Além disso, o sensoriamento remoto surge como uma importante ferramenta para a obtenção de dados espaciais, na medida em que fornece informações por preços reduzidos, além de possibilitar reduções de trabalhos de campo, que, consequentemente, aumentam os custos do produto final.

Nesse sentido, o sensoriamento remoto pode ser entendido como a utilização conjunta de sensores, equipamentos para processamentos e dados, com o objetivo de estudar o ambiente terrestre através do registro de análise das interações entre radicação eletromagnética e os objetos da superfície terrestre (NOVO, 1988).

Os sensores mais popularizados atualmente são os sensores de satélites que captam imagens a partir da órbita terrestre. Florenzano (2011) aponta que as imagens obtidas através do sensoriamento remoto permitem uma visão sinóptica do meio ambiente ou da paisagem possibilitando estudos regionais e integrados, envolvendo vários campos do conhecimento.

Segundo Sausen (2005), a utilização do sensoriamento remoto, e de ferramentas de geoprocessamento, permitem diagnósticos eficientes, propõem soluções de baixo custo e criam alternativas inteligentes para os desafios enfrentados face às mudanças aceleradas que se observam em nosso território.

A partir dessas perspectivas, é visto que geotecnologias, em geral, trouxeram novas possibilidades de representar e analisar a paisagem. O SIG, em particular, abriu a possibilidade para representações multiescalares e para bases de dados que contenham versões digitais do conteúdo de muitos mapas em diferentes escalas (GOODCHILD e QUATTROCHI, 1997).

Sobre esse ponto de vista, o sistema de informações geográficas permite o manuseio de diferentes escalas, resoluções e naturezas dos dados. O SIG abre uma perspectiva de incorporação à sua base de dados, de documentos em diferentes escalas e 
resoluções, através de mapas, informações e imagens, as vezes bastante diversas uma das outras (MENEZES E NETTO, 1999).

As potencialidades do SIG revolucionaram as análises geográfica, sobre os aspectos de escala e natureza dos dados, que antes eram realizadas em meios analógicos e sem potencialidades de otimização para os estudos. Um recurso primordial em SIG é a possibilidade de análise vertical e horizontal. Para Lang e Blaschke (2009), quando uma paisagem é analisada horizontalmente é avaliado as suas relações laterais e de vizinhança, quando são analisadas verticalmente, diferentes camadas são analisadas de forma integrada, sobrepostas e combinadas, possibilitando diversas inferências.

A análise da paisagem apoiada em SIG objetiva fundamentalmente gerar novas informações, o que se dá por meio da manipulação e integração com camadas de dados já existentes (LANG E BLASCHKE, 2009). É nesse sentido que as análises espaciais podem apoiar a tomada de decisões referentes às paisagens.

\section{Considerações finais}

Conforme visto, a escolha apropriada para a escala espacial depende da dimensão do fenômeno, bem como, o grau de detalhamento e informações necessárias para a compreensão do objeto. O mesmo ocorre para a escala temporal, tendo em vista a sucessão de acontecimentos e a compreensão da dinâmica existente na paisagem analisada, sendo importante o recorte apropriado ao entendimento do fenômeno escolhido.

As ferramentas geotecnológicas possuem inúmeras funcionalidades na análise da paisagem, sendo de suma importância para análises geográficas de qualquer natureza. Dessa forma, as metodologias de análise da paisagem têm adquirido cada vez mais recursos nas geotecnologias, por otimizar tempo e custos para diferentes tipos de estudos, tal como a análise da trajetória evolutiva da paisagem.

\section{Referências bibliográficas}

BERTRAND, G. Paisagem e Geografia Física Global: esboço metodológico. In: Caderno de Ciências da Terra. No 13. São Paulo: Revista IG-USP, 1971.

CASTRO, I. E. Análise geográfica e o problema epistemológico da escala. Anuário do Instituto de Geociências, 1992, 15: 21-25.

CÂMARA, G.; MONTEIRO, A.M.V.; MEDEIROS, J.S. Fundamentos epistemológicos da ciência da geoinformação. In: CÂMARA, G.; DAVIS, C.; MONTEIRO, A.M.V. Introdução à ciência da Geoinformação. São José dos Campos: INPE, 2001.

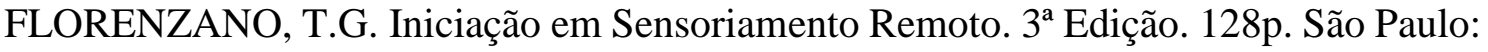
Oficina de Textos, 2011.

GOODCHILD, M. F. \& QUATTROCHI, D. A. Scale, Multiscaling, Remote Sensing, and Gis. In: Scale in Remote Sensing and Gis. CRC Press. 1997.

KOHLER, H. C. A escala na análise geomorfológica. Revista Brasileira de Geomorfologia, v. 3, n. 1, 2002. 
LANG, S.; BLASCHKE, T. Análise da paisagem com SIG. Tradução de Hermann Kux. São Paulo: Oficina de Textos, 2009.

MARQUES, A. J., \& GALO, M. D. L. B. T. (2009). Escala geográfica e escala cartográfica: distinção necessária. Boletim de Geografia, 47-55.

MENEZES, P. M. L. \& NETTO, A. L. C. Escala: Estudo de Conceitos e Aplicações. Rio de Janeiro: $1999 . \quad$ Disponível em http://www.geocart.igeo.ufrj.br/pdf/trabalhos/Escala_Conceitos_Aplic.pdf. Acessado em: $26 / 08 / 2018$.

MENEZES, P. M. L.; FERNANDES, Manoel. Roteiro de cartografia. Oficina de Textos, 2013.

MONTEIRO, C. A. de F. Geossistema: a história de uma procura. São Paulo: Contexto (Coleção Novas Abordagens, n.3), 2000.

NOVO, E. M. L. M. Sensoriamento Remoto, Princípios e Aplicações - Edgard Blucher, 1998.

OLIVEIRA, R.F.C.A. O conceito de escala e os mapas no ensino de geografia: considerações sobre uma atividade prática de pesquisa em ambiente escolar. In: I Seminário Internacional dos Espaços de Fronteira. Paraná: UNIOESTE, 2011. Disponível em: http://cacphp.unioeste.br/eventos/geofronteira/anais2011/Arquivos/Artigos/ENSINO/Artigo41.pd f. Acessado em: 12/12/2018.

ROSA, R. Geotecnologias na Geografia Aplicada. Revista do Departamento de Geografia (USP), São Paulo, v. 16, p. 81-90, 2005.

SAUSEN, T. M. Sensoriamento Remoto e suas aplicações para recursos naturais. Instituto Nacional de Pesquisas Espaciais. (http://www.herbario.com.br/) São José dos Campos-SP. 2005.

SEABRA, V. S. Geotecnologias e Estudos Ambientais: Conceitos e Aplicações. Revista Ambientale, v. 1, p. 27-36, 2009.

TROLL, C. A paisagem geográfica e sua investigação. Espaço e cultura, n. 4, p. 1-7, 1997.

ZACHARIAS, A.A. A representação gráfica das unidades de paisagem no zoneamento ambiental: um estudo de caso no município de Ourinhos-SP. Tese (Doutorado em Geografia), Instituto de Geociências e Ciências Exatas, Universidade Estadual Paulista, Rio Claro, 2006, $209 \mathrm{f}$. 